\title{
Dobutamine stress echocardiography: a review and update
}

This article was published in the following Dove Press journal:

Research Reports in Clinical Cardiology

5 April 2014

Number of times this article has been viewed

\section{Lauren Gray Gilstrap' \\ R Sacha Bhatia ${ }^{2}$ \\ Rory B Weiner ${ }^{3}$ \\ David M Dudzinski ${ }^{3}$}

'Division of Cardiology, Brigham and Women's Hospital, Boston, MA, USA; ${ }^{2}$ Institute for Health Systems Solutions, Women's College Hospital, Toronto, ON, Canada; ${ }^{3}$ Cardiology Division, Massachusetts General Hospital, Boston, MA, USA
Correspondence: David M Dudzinski Cardiology Division, Massachusetts General Hospital, 55 Fruit Street, Boston, MA, USA

Tel +l 6177262677

Fax + I 6177246767

Email ddudzinski@partners.org
Abstract: Stress echocardiography is a noninvasive cardiovascular diagnostic test that provides functional and hemodynamic information in the assessment of a number of cardiac diseases. Performing stress echocardiography with a pharmacologic agent such as dobutamine allows for simulation of increased heart rate and increased myocardial physiologic demands in patients who may be unable to exercise due to musculoskeletal or pulmonary comorbidities. Dobutamine stress echocardiography (DSE), like exercise echocardiography, has found its primary application in ischemic heart disease, with roles in identification of obstructive epicardial coronary artery disease, detection of viable myocardium, and assessment of the efficacy of anti-ischemic medical therapy in patients with known coronary artery disease. DSE features prominently in the evaluation and management of valvular heart disease by helping to assess the effects of mitral and aortic stenoses, as well as a specific use in differentiating true severe valvular aortic stenosis from pseudostenosis that may occur in the setting of left ventricular systolic dysfunction. DSE is generally well tolerated, and its side effects and contraindications generally relate to consequences of excess inotropic and/or chronotropic stimulation of the heart. The aim of this paper is to review the indications, contraindications, advantages, disadvantages, and risks of DSE.

Keywords: stress echocardiography, dobutamine, coronary artery disease, myocardial ischemia

\section{Introduction}

Stress echocardiography is a procedure that allows for the dynamic evaluation of cardiac structure and function during physical exercise or the pharmacologic simulation of exercise by increased heart rate, cardiac output, and myocardial oxygen demand. While exercise stress echocardiography provides physiologic information, echocardiographic imaging in pharmacologic stress tests is facilitated by the lack of both exercise-related chest wall motion and increased respirations. ${ }^{1}$ Stress echocardiographic imaging techniques may be used to evaluate for myocardial ischemia, viability, and valvular dysfunction.

Compared with traditional radionuclide imaging, pharmacologic stress echocardiography has the advantage of not requiring specialized radiopharmaceuticals or radionuclide imaging equipment. In contrast with radionuclide imaging, echocardiographic images can be obtained anywhere along the continuum from rest to peak physiologic stress. Dobutamine stress echocardiography (DSE) avoids radiation and enjoys relatively high sensitivity and specificity for multiple types of cardiovascular pathophysiology. For these reasons, its utility and applicability are increasing in clinical practice. 
This paper reviews the principles, procedure, and technique of DSE and discusses the indications, contraindications, advantages, and disadvantages of this method of cardiovascular imaging.

\section{Principles of pharmacologically induced stress}

Exercise-induced physiologic stress is preferred so that a patient's functional capacity can be determined and symptoms can be reproduced. All major echocardiographic guidelines recommend exercise stress echocardiography over pharmacological stress echocardiography since exercise provides a simultaneous physiologic assessment of functional capacity and symptom onset. However, many cardiac patients are unable to exercise on a treadmill or a bicycle due to orthopedic, rheumatologic, or pulmonary comorbidities. For these patients, pharmacologic stress should be pursued. ${ }^{2}$ Commonly used pharmacologic stressors include vasodilators such as adenosine and dipyridamole, or inotropes, such as dobutamine.

Dobutamine is an adrenergic agonist, traditionally used in intensive care units or in end-stage heart failure. Dobutamine acts on $\beta 1$-adrenergic receptors to increase cardiac contractility and heart rate, and on $\beta 2$-adrenergic receptors to cause peripheral vasodilatation. It also has a mild effect on $\alpha 1$-adrenergic receptors, which causes vasoconstriction, but this effect is outweighed by the more potent $\beta 2$-mediated vasodilatation. The onset of action of dobutamine is 1-2 minutes and the plasma half-life is approximately 2 minutes. $^{3}$

The goal of DSE is to detect myocardial ischemia early in the progression of coronary disease by identifying regional wall motion abnormalities ${ }^{4}$ under conditions of pharmacologic stress. In the context of stress echocardiography, dobutamine temporarily increases myocardial oxygen consumption and thereby can provoke ischemia. Coronary flow limitation initially causes diastolic dysfunction because lusitropy is an energy-intensive process. Diastolic dysfunction often precedes other manifestations of ischemia, including the visualization of systolic dysfunction.

\section{Performance of DSE Procedure and technique}

The protocol for the standard DSE examination was defined in the 2007 American Society of Echocardiography (ASE) guidelines. ${ }^{2}$ A graded dobutamine infusion is given typically at a starting dose of $5 \mu \mathrm{g} / \mathrm{kg}$ per minute. The goal of the dobutamine infusion is to achieve a heart rate $85 \%$ of the maximal predicted heart rate for the patient's age. Accordingly, the dobutamine dose is increased every 3-5 minutes to doses of 10,20 , and 30 , and finally to $40 \mu \mathrm{g} / \mathrm{kg}$ per minute.

Dobutamine is metabolized hepatically and in peripheral tissues, but there is no set dose reduction for those with hepatic or renal dysfunction. There is also no set reduction in geriatric patients, even though the US Food and Drug Administration recommends "cautious" dosing in the elderly. ${ }^{5}$ Each echocardiography laboratory may specify a local protocol of minimal and maximal doses and stages. ${ }^{6}$

The low-dose dobutamine stage is optimal for detection of ischemia and assessment of viability by searching for the "biphasic response" where a myocardial territory augments its contraction at a low inotrope dose but later becomes hypokinetic or akinetic at higher dobutamine doses. Therefore, if viability assessment is the principal aim, the initial dose is often lowered to $2.5 \mu \mathrm{g} / \mathrm{kg}$ per minute.

If the heart rate target is not achieved with dobutamine infusion alone, atropine (maximum total dose $2 \mathrm{mg}$, typically divided into four $0.5 \mathrm{mg}$ doses) can be added, ${ }^{7}$ which increases the sensitivity of stress echocardiography in patients with single-vessel disease ${ }^{8}$ or who are on chronic beta-blockers. ${ }^{9}$ Some practitioners also consider a trial of an increased dose of dobutamine ( $50 \mu \mathrm{g} / \mathrm{kg}$ per minute) if the patient is very close to achieving the $85 \%$ maximal predicted heart rate target. In some laboratories, gentle hand, arm, or leg exercises are also used for chronotropic augmentation when close to target heart rate, provided these motions do not impair the echocardiography examination, electrocardiography (ECG) tracings, or blood pressure monitoring, and the patient is able to perform them.

End points of the DSE protocol include achievement of the target heart rate, detection of moderate wall motion abnormalities in at least two territories, symptomatic or sustained arrhythmias, hypotension or severe hypertension (typically systolic pressure $>220-240 \mathrm{mmHg}$ or diastolic pressure $>120 \mathrm{mmHg}$ ), or the patient's inability to tolerate the test. In some cases, reversal of wall motion abnormalities is assessed with addition of post-stress betablockers (typically 1-5 mg of intravenous metoprolol). Beta-blockers given in recovery may, paradoxically, enhance ischemia by reversing dobutamine-facilitated vasodilatation and abruptly causing vasoconstriction (through a mechanism of $\beta 1$ and also $\beta 2$ antagonism with relatively unopposed $\alpha 1$-mediated vasoconstriction). ${ }^{10,11}$ In addition, adjunct beta-blockers in recovery may better unmask subendocardial wall motion abnormality that may be difficult to distinguish from hyperdynamic contraction of mid and epicardial layers. ${ }^{10,11}$ Similarly, in viability 
assessments, sensitivity can be increased by employing a beta-blocker protocol for scoring of recovery phase wall motion abnormalities. ${ }^{12}$

The sensitivity of DSE for detection of myocardial ischemia may be reduced by long-term beta-blockers, calcium channel blockers, and nitrates. ${ }^{13,14}$ However, when a patient chronically takes one of these anti-ischemic drugs, a positive test for ischemia is more significant, although a negative test may be less helpful. Many practitioners choose to test a patient with known coronary artery disease (CAD) on their anti-ischemic regimen to investigate for the presence of ischemia and assess whether anti-ischemic medical therapy has been optimized.

\section{Testing procedure}

Patients typically fast for 4 hours prior to the test. All negative chronotropic agents and nitrates should be held 8-12 hours before DSE, unless the goal is to assess the efficacy of the anti-ischemic medical regimen, as described above. The testing should be performed in an accredited stress echocardiography laboratory equipped with appropriate echocardiographic equipment and medications. ASE quality guidelines mandate that the cardiac ultrasound devices have the ability to trigger image acquisition based on the ECG and also suggest that the laboratory employ machines with split-screen and quadruple-screen display to facilitate simultaneous comparison from rest to peak to post-stress images. ${ }^{6}$

Staffing should include a physician, nurse, and sonographer. The data support the safety of stress echocardiography supervised by a registered nurse along with a sonographer and ECG technician, who all work in conjunction with a physician in the echocardiography laboratory. ${ }^{15}$ During the stress procedure, the sonographer obtains echocardiographic images by applying the transducer to obtain images in the parasternal (or apical) long axis, parasternal short axis (at mitral valve, mid ventricle, and apical levels), and apical four chamber and two chamber windows. Contrast enhancement should be considered to augment endocardial definition when two or more contiguous left ventricle endocardial segments cannot be visualized at rest; the ASE guideline notes that this will occur in approximately $<10 \%$ of stress echocardiograms. ${ }^{6}$ During a DSE, images of the left ventricle at each echocardiographic window are obtained during rest, low-dose dobutamine, peakdose dobutamine, and post-stress. Attention must be paid to profile the exact same echocardiographic plane (and at the same depth) during stress imaging to facilitate comparison with baseline images and to permit accurate identification of wall motion abnormality.

\section{Testing interpretation}

Each stress report must comment on the adequacy of stress (achievement of target heart rate or estimated workload), symptoms, blood pressure response, and any electrocardiographic (ischemic or arrhythmic) and echocardiographic changes. The typical stress echocardiography report should comment both on global left ventricular function and regional left ventricle function, along with a summative comment on the significance of the findings. Per ASE guidelines, regional wall motion abnormalities are assessed on the basis of a 16-segment model of the left ventricle. Other cardiology guidelines, including for myocardial perfusion imaging, employ a 17-segment model that includes the apical cap, but because the normal tip of the apex may not move, wall motion is typically not assessed there on echocardiography. At stress echocardiography, an ischemic response is generally defined as decreased wall thickening in at least one segment. However, when interpreting ischemia, readers should be cognizant of possible false positive reads in single segments such as the inferior basal segment in a short axis view, and attempt to confirm the same wall motion abnormality in the same segment in multiple views when possible. Multiple views may not be able to be obtained of some apical segments, and thus ischemia based on a single abnormal segment there is reasonable. Unlike for viability which requires two echocardiographic segments, ASE guidelines do not stipulate that more than one ischemic segment is required to document ischemia. Basing ischemia on a single segment will result in a test protocol very sensitive for ischemia but at the expense of possible false positive results; requiring two or more segments will decrease sensitivity but increase specificity for diagnosis of CAD. In general, we would diagnose ischemia at stress echocardiography based on decreased wall thickening in two or more contiguous segments (except for apical segments) occurring at peak dose; our preference for two contiguous segments reflects an aim to preserve high specificity of the test. Extrapolating from the 2011 Appropriate Use Criteria, ${ }^{16}$ indication \#202 gives an appropriate rating to use of left ventricular opacification agents when two or more contiguous segments are not well visualized, thus highlighting the need to visualize contiguous segments to diagnose ischemia. For those studies designed to assess cardiovascular parameters besides ischemia, the report may be required to discuss results on myocardial viability, presence of arrhythmias, degree of valvular stenosis or regurgitation, estimated right ventricular systolic pressure, or diastology. ${ }^{17,18}$ Each laboratory should enact a local policy documenting the critical values that require urgent communication to the 
requesting physician and/or transfer to a facility for ongoing care; some of these high-risk findings may include significant inducible ischemia associated with ischemic dilatation and/ or hypotension, ST segment elevations, ventricular tachycardia, or other major complications. Communication with the requesting physician in these instances should be documented in the DSE report.

\section{Contraindications to DSE}

Contraindications to DSE are related to the administration of dobutamine, and include ventricular arrhythmias, recent myocardial infarction (within 3 days), unstable angina, significant left ventricular outflow obstruction (for example, resting peak late systolic pressure gradient $\geq 30 \mathrm{mmHg}$, although in our laboratory we use $\geq 50 \mathrm{mmHg}$ in selected patients), aortic dissection, and severe (resting systolic blood pressure $>180 \mathrm{mmHg}$ or diastolic blood pressure $>100 \mathrm{mmHg}$ ) or symptomatic hypertension. ${ }^{2}$ The practitioner should also be cognizant of other cardiac pathologies that may be adversely affected by increases in heart rate and/or blood pressure, including aortic aneurysms, ${ }^{19}$ carotid disease, heart failure and cardiomyopathy, intracranial aneurysms, ${ }^{20}$ and history of stroke or transient ischemic attack. Even in the presence of known abdominal aortic aneurysms ( $\geq 4 \mathrm{~cm}$ ) and intracranial aneurysms, DSE appears to be a safe modality for cardiac risk stratification, although the practitioner may reasonably substitute a vasodilator stress modality in such patients. ${ }^{19,20}$

\section{Complications}

Data from 26 studies in a meta-analysis reported the incidence of potentially life-threatening complications of DSE at $<0.01 \%,{ }^{21}$ as detailed in Table 1 . Complications such as

Table I Incidence, mechanism, and treatment of the complications of dobutamine stress echocardiography

\begin{tabular}{|c|c|c|c|c|}
\hline Complication & Incidence & Incidence (range) & Mechanism & Treatment \\
\hline \multicolumn{5}{|l|}{ Overall } \\
\hline Mortality & $<0.01 \%$ & $0.00 \%-0.01 \%$ & VF, cardiac rupture & Per underlying cause \\
\hline \multicolumn{5}{|l|}{ Mechanical complications } \\
\hline Cardiac rupture & $<0.01 \%$ & $0.00 \%-0.01 \%$ & $\begin{array}{l}\text { Rupture of akinetic or } \\
\text { dyskinetic segments }\end{array}$ & $\begin{array}{l}\text { Stop dobutamine, } \pm \text { pericardiocentesis, } \\
\pm \text { surgery }\end{array}$ \\
\hline Coronary spasm & $0.14 \%$ & $\begin{array}{l}\text { True incidence } \\
\text { unknown }\end{array}$ & $\begin{array}{l}\alpha \mathrm{I} \text {-receptor mediated } \\
\text { vasoconstriction }\end{array}$ & $\begin{array}{l}\text { Sublingual nitroglycerin (note beta-blocker } \\
\text { would worsen spasm, consider long-term } \\
\text { calcium channel blockade) }\end{array}$ \\
\hline \multicolumn{5}{|l|}{ Thrombotic complications } \\
\hline Myocardial infarction & $0.02 \%$ & $0.00 \%-0.1 \%$ & Plaque rupture, platelet aggregation & Stop dobutamine, coronary revascularization \\
\hline $\begin{array}{l}\text { Cerebrovascular } \\
\text { accident }\end{array}$ & $<0.01 \%$ & $0.00 \%-0.1 \%$ & $\begin{array}{l}\text { Embolism, shearing forces } \\
\text { with increased BP }\end{array}$ & Stop dobutamine, MRI, neurology evaluation \\
\hline \multicolumn{5}{|c|}{ Arrhythmia complications } \\
\hline Asystole & $<0.01 \%$ & $0.00 \%-0.03 \%$ & $\begin{array}{l}\text { Sinus node deceleration or } \\
\text { arrest due to ischemia }\end{array}$ & $\begin{array}{l}\text { Stop dobutamine, atropine bolus } \\
(0.5-2 \mathrm{mg}), \pm \text { pacing }\end{array}$ \\
\hline Ventricular fibrillation & $0.04 \%$ & $0.00 \%-0.18 \%$ & Underlying ischemia and/or scar & Stop dobutamine, initiate ACLS \\
\hline $\begin{array}{l}\text { Sustained ventricular } \\
\text { tachycardia }\end{array}$ & $0.15 \%$ & $0.00 \%-0.78 \%$ & $\begin{array}{l}\text { Effect on QTc, increased } \\
\text { intracellular calcium which } \\
\text { triggers automaticity }\end{array}$ & $\begin{array}{l}\text { Stop dobutamine, administer IV beta-blockade } \\
(5-10 \mathrm{mg}) \text {, administer IV procainamide or } \\
\text { amiodarone, cardiovert if unstable }\end{array}$ \\
\hline SVT & $\begin{array}{l}\text { PAC } 7.8 \% \\
\text { SVT I.3\% } \\
\text { AFib } 0.9 \%\end{array}$ & $\begin{array}{l}\text { PAC }(0.7 \%-27.8 \%) \\
\text { SVT }(0.0 \%-7 \%) \\
\text { AFib }(0.3 \%-2.2 \%)\end{array}$ & $\begin{array}{l}\text { More common in patients } \\
\text { with decreased EF, increased } \\
\text { left atrial size and pressure }\end{array}$ & $\begin{array}{l}\text { Stop dobutamine, administer beta-blocker } \\
(5-10 \mathrm{mg}) \text {, verapamil }(10 \mathrm{mg}) \text { or digoxin } \\
(0.5 \mathrm{mg}) \text {, cardioversion if unstable }\end{array}$ \\
\hline $\begin{array}{l}\text { Atrioventricular } \\
\text { block }\end{array}$ & $0.23 \%$ & $0.03 \%-0.68 \%$ & $\begin{array}{l}\text { Myocardial ischemia, } \\
\text { Bezold-Jarisch reflex, latent } \\
\text { abnormalities of His-Purkinje } \\
\text { system }\end{array}$ & $\begin{array}{l}\text { For Mobitz I, stop dobutamine and administer } \\
\text { atropine } \\
\text { For Mobitz II, stop dobutamine (atropine may } \\
\text { worsen block); assess for myocardial ischemia } \\
\text { (usually seen with wall motion abnormality) }\end{array}$ \\
\hline Hypotension & $1.7 \%$ & $0.2 \%-7.6 \%$ & $\begin{array}{l}\beta 2 \text { agonist reduces SVR; inadequate } \\
\text { increase in cardiac output to } \\
\text { compensate for decrease in SVR }\end{array}$ & $\begin{array}{l}\text { Stop dobutamine, Trendelenburg position, } \\
\text { IV fluids, consider atropine }\end{array}$ \\
\hline Hypertension & $1.3 \%$ & $0.2 \%-5.5 \%$ & $\begin{array}{l}\text { More common in patients with } \\
\text { a history of HTN or intermittent } \\
\text { beta-blocker use }\end{array}$ & $\begin{array}{l}\text { Stop dobutamine, administer IV beta-blockers } \\
\text { or vasodilator as needed }\end{array}$ \\
\hline
\end{tabular}

Notes: Data from Geleijnse et al. Incidence, pathophysiology, and treatment of complications during dobutamine-atropine stress echocardiography. Circulation. 2010;121: $1756-1767 . .^{93}$

Abbreviations: ACLS, advanced cardiac life support; AFib, atrial fibrillation; BP, blood pressure; EF, ejection fraction; HTN, hypertension; IV, intravenous; MRI, magnetic resonance imaging; PAC, premature atrial contraction; SVR, systemic vascular resistance; SVT, supraventricular tachycardia; VF, ventricular fibrillation. 
ventricular arrhythmias are more common in patients with high-grade ischemic disease and those with left ventricular dysfunction (ejection fraction $<35 \%$ ), and may occur more frequently when higher doses of dobutamine are used. Despite this relatively safe profile, approximately half of patients experience some reaction to the dobutamine infusion, including nausea, flushing, headache and neck/chest pounding, paresthesia, urinary urgency, palpitations, or dyspnea. Atropine is relatively safe but due to its anticholinergic properties it may cause urinary retention, increased intraocular pressure, delirium, ${ }^{22}$ flushing, constipation and delayed gastric emptying, nausea, dry mouth, and weakness.

\section{Clinical utility and indications for DSE}

In general, DSE is used to evaluate for the presence and/or extent of CAD, but there are other specific indications detailed in the 2007 ASE guidelines (Table 2). ${ }^{2}$ These include ischemic heart disease risk stratification, valvular disease, pulmonary hypertension, hypertrophic cardiomyopathy, dyspnea evaluation, pretransplant evaluation, and assessment of "hibernating" myocardium. In addition, in the 2011 Appropriate Use Criteria for echocardiography was jointly published by multiple professional societies. The Appropriate Use Criteria highlights common clinical scenarios describing the appropriate and inappropriate use of stress echocardiography, ${ }^{16}$ and mirrors practice guidelines when able.

\section{Ischemic evaluation}

The most common indication for stress echocardiography is evaluation of myocardial ischemia. ${ }^{23,24}$ The basic principle

Table 2 Indications for dobutamine stress echocardiography

\begin{tabular}{ll}
\hline Indication & Assessment \\
\hline $\begin{array}{l}\text { Risk stratification } \\
\text { of ischemic heart disease }\end{array}$ & $\begin{array}{l}\text { Presence and extent of ischemic } \\
\text { myocardium as well as viable and/or } \\
\text { hibernating myocardium } \\
\text { Indicated in asymptomatic patients } \\
\text { Mith severe mitral stenosis, patients } \\
\text { showing symptoms discordant with rest } \\
\text { echocardiographic measures of stenosis, } \\
\text { and assessment of transvalvular } \\
\text { gradients at stress } \\
\text { Differentiation of low gradient aortic } \\
\text { stenosis versus pseudostenosis, and } \\
\text { prognosis in low gradient aortic stenosis } \\
\text { (eg, assessment of contractile reserve) } \\
\text { Assessment of pulmonary artery } \\
\text { systolic pressure at stress when patient } \\
\text { is unable to exercise }\end{array}$ \\
\hline
\end{tabular}

Notes: Data from: Pellikka PA, Nagueh SF, Elhendy AA, et al. American Society of Echocardiography Recommendations for Performance, Interpretation, and Application of Stress Echocardiography. J Am Soc Echocardiogr. 2007;20: 1021-1041.2 is identification and localization of areas of ischemia by detecting new or worsening wall motion abnormalities. Stress echocardiography can be used to assess for ischemia in patients with or without a prior diagnosis of CAD. For patients without a prior diagnosis of CAD, stress echocardiography can be used to detect inducible ischemia. ${ }^{25,26}$ For patients with a known history of CAD, stress echocardiography can be used to assess the extent and severity of ischemia. ${ }^{27,28}$

Stress echocardiography has the highest specificity (88\%) among the ischemic tests including traditional exercise ECG testing, thallium perfusion imaging, single photon emission computed tomography (SPECT), and positron emission tomography (PET).$^{29}$ Accounting for differences in costs, stress echocardiography seems to be more efficient than SPECT. The incremental cost-effectiveness ratio for SPECT is $\$ 75,000$ per quality-adjusted life year more than stress echocardiography, and the incremental cost-effectiveness ratio for PET is $\$ 640,000$ per qualityadjusted life year more than SPECT. ${ }^{29}$ Another metaanalysis directly compared stress echocardiography and SPECT for detection of CAD, and showed no difference in sensitivity but a significantly higher specificity for exercise stress echocardiography (77\%) compared with SPECT imaging $(64 \%) .{ }^{30}$

As a result of its high specificity, stress echocardiography enjoys robust negative predictive values for both myocardial infarction and cardiac death. A large meta-analysis studying stress echocardiography with exercise quoted a negative predictive value of $98.4 \%$ over a 33 -month follow-up..$^{31}$ There is no reported sex difference in the diagnostic or prognostic utility of stress echocardiography (see DSE in women heading) ${ }^{31} \mathrm{~A}$ large multicenter, 5-year study of 4,234 women and 6,898 men undergoing stress echocardiography for CAD risk stratification found that echocardiographic measures of inducible wall motional abnormalities and global and regional left ventricular function were predictive of long-term outcomes for both men and women. ${ }^{32}$

More recent data suggest that in patients with left ventricular hypertrophy, stress echocardiography may be the test of choice in an ischemic evaluation. ${ }^{33}$ ECG repolarization abnormalities caused by left ventricular hypertrophy, even in the absence of baseline ECG abnormalities, often confound the diagnostic accuracy of exercise ECG testing. In addition, heterogenous uptake of radionuclide due to left ventricular hypertrophy may generate a higher false positive rate of perfusion imaging tests, but this limitation is not applicable to stress echocardiography. 


\section{Myocardial viability}

Determining myocardial viability is one of the most clinically useful applications of DSE. "Hibernating" myocardium refers to viable but underperfused myocardial tissue that regains functionality after revascularization. ${ }^{34,35}$ Rescue of hibernating myocardium via revascularization manifests as improved left ventricular function due to recruitment of the affected territory. ${ }^{36-38}$ DSE has emerged as a noninvasive tool for detecting hibernating myocardium and thus identifying patients most like to benefit from revascularization in a myriad of clinical scenarios. ${ }^{39}$

At low doses of dobutamine, hibernating myocardium will augment due to inotropic stimulation (eg, a manifestation of contractile reserve). At progressively higher doses of dobutamine, the hibernating segment may exhibit abnormal wall motion due to the compromised coronary blood flow being insufficient to meet the increased metabolic demands. This pattern of wall motion is termed the "biphasic" response, and it appears to be most predictive of post-revascularization viability (as compared with patterns of "uniphasic" worsening or sustained improvement in wall motion). ${ }^{40,41}$ ASE guidelines recommend that viability assessment at a minimum includes improvement in at least two echocardiographic left ventricular segments. ${ }^{2}$ Four or more segments out of a total of 16 displaying a biphasic response exhibited a specificity of $81 \%$ for predicting a $\geq 5 \%$ increase in post-revascularization ejection fraction at a median 14-month follow-up of chronic ischemic cardiomyopathy, with a sensitivity of $83 \%$ if the ejection fraction was $>35 \%$ and of $92 \%$ if the ejection fraction was $\leq 35 \% .{ }^{40}$ Another study of 133 patients with chronic ischemic cardiomyopathy and an ejection fraction $<40 \%$ showed that identification of six segments with biphasic response had greater predictive power for predicting postrevascularization freedom from cardiac events than a lower number, eg, two to five biphasic segments. ${ }^{42}$

DSE performed one week after myocardial infarction that documents the presence of either an ischemic or biphasic response has a sensitivity of $82 \%$ and a specificity of $80 \%$ for detecting a residual stenosis subtending an area of hibernating myocardium.$^{43}$ The presence of myocardial viability early after a myocardial infarction is the single best predictor of recurrent in-hospital ischemia and unstable angina after discharge. Patients with myocardial viability identified on DSE have a $20 \%$ chance of recurrent in-hospital ischemia versus a $7 \%$ risk in patients without viable myocardium. ${ }^{44}$ While this result suggests that presence of viable myocardium counterintuitively portends a poorer prognosis, it is important to also note that the presence of viable myocardium after myocardial infarction is also associated with better left ventricular function recovery and lower long-term mortality. ${ }^{45}$

Myocardial viability identified with stress echocardiography is associated with improved survival after revascularization in patients with $\mathrm{CAD}^{46}$ and ischemic cardiomyopathy. ${ }^{47}$ Specifically in patients with ischemic cardiomyopathy, DSE is helpful in identifying patients most likely to have improved survival by undergoing percutaneous revascularization or coronary artery bypass grafting. For patients with stable $\mathrm{CAD}$, the biphasic response on DSE is useful in predicting ultimate post-revascularization left ventricular recovery. ${ }^{48}$ Furthermore, nitroglycerin has been shown to be useful in enhancing the sensitivity of DSE to detect viable myocardium in animal models; ${ }^{49}$ however, its clinical efficacy in human patients remains controversial. In a study of 32 patients, the combined nitroglycerin and dobutamine stress echocardiogram had the highest specificity (83\%) but rest-redistribution thallium single proton emission tomography had the highest sensitivity (95\%) for detecting viable myocardium.

\section{Valvular disease}

Stress echocardiography has the ability to comprehensively assess valvular function, both at rest and during stress, and indirectly evaluate hemodynamics in real time. Stenosis and regurgitation of all valves can be evaluated with stress echocardiography, although the most common stress echocardiogram applications are in left-sided stenotic lesions. Exercise echocardiography is the general technique for assessment of valvular disease except in aortic stenosis with left ventricular dysfunction. There are limited data for assessment of aortic regurgitation and mitral regurgitation by DSE, as there is concern that the afterload-reducing properties of dobutamine will reduce the degree of valvular regurgitation. ${ }^{50}$ Monitoring of tricuspid regurgitation velocity is commonly done for the purpose of pulmonary pressure estimation, which bears on the assessment of the severity of left-sided valvular lesions.

\section{Mitral stenosis}

The 2007 ASE guidelines recommend stress echocardiography for evaluation of asymptomatic patients with echocardiographically severe mitral stenosis and patients with symptoms disproportionate to their echocardiographic disease. It is important to note that stress echocardiography is still not recommended for routine evaluation of mitral stenosis in the absence of severe symptoms, severe stenosis by rest echocardiography, or a clinically meaningful discrepancy in symptoms and echocardiography. ${ }^{51}$ 
The ability to evaluate both valvular function and dynamic transvalvular gradients is particularly helpful in patients whose symptoms are more severe than their resting echocardiographic evaluation would suggest. ${ }^{1}$ A multivariate analysis of patients with rheumatic mitral stenosis defined a mean transmitral gradient $\geq 18 \mathrm{mmHg}$ at DSE as "high risk" and the best predictor of future clinical events (eg, heart failure related to mitral stenosis, surgical or balloon intervention, hemodynamically significant arrhythmia, or death) with a sensitivity of $90 \%$ and a specificity of $87 \% .^{52}$ These high-risk patients likely warrant more aggressive clinical care and consideration for earlier more aggressive interventions.

\section{Aortic stenosis}

Stress echocardiography is contraindicated in patients with severe symptomatic aortic stenosis. ${ }^{51}$ For seemingly asymptomatic patients even with echocardiographically severe aortic stenosis, low-level exercise stress echocardiography can confirm their asymptomatic status and exclude the possibility of patients minimizing their symptoms by insidiously downgrading their level of activity so as to not perceive symptoms.

Patients with a low left ventricular ejection fraction $(<35 \%-40 \%)$ and a low mean transvalvular gradient $(<30-40 \mathrm{mmHg})$, called "low-gradient aortic stenosis", pose a diagnostic dilemma. ${ }^{51}$ This is one of the clinical situations where DSE is uniquely helpful. In these patients, it is often very difficult to determine if they have true valvular stenosis, and thus should be considered for valve replacement, or instead have "pseudostenosis", namely left ventricular contractile dysfunction that makes the aortic valve appear stenotic, but carries a high risk of dying with valve replacement. DSE can be useful in differentiating these patients and determining who might benefit from surgical intervention.

Specifically, patients with aortic valve pseudostenosis are able to increase their aortic valve area and decrease the transaortic gradient in response to the effect of dobutamine on cardiac contractility and increased cardiac output. ${ }^{53,54}$ In contrast, patients with true aortic stenosis are unable to increase their valve area in response to an increased cardiac output, and instead the transvalvular gradient increases. ${ }^{54,55}$ DSE can also be used to risk stratify patients with aortic stenosis and predict long-term valve-related outcomes. For patients with low gradient aortic stenosis, surgery is most beneficial for those with documented left ventricular contractile reserve. Contractile reserve is defined as a $20 \%$ increase in stroke volume (as assessed by the left ventricular outflow tract velocity time integral) or a $20 \%$ relative increase in ejection fraction. ${ }^{56}$ The postoperative outcomes for patients with low gradient aortic stenosis and without contractile reserve is poor (odds ratio for perioperative death, $10.9 ; 95 \%$ confidence interval 2.6-43.4)..$^{57,58}$

\section{Specific transcatheter aortic valve replacement}

DSE is particularly helpful in determining appropriate candidates for transcatheter aortic valve replacement. ${ }^{59}$ Current guidelines define "severe aortic stenosis" as an aortic valve area $\leq 1 \mathrm{~cm}^{2}$ or a mean aortic valve gradient of $\geq 40 \mathrm{mmHg} .{ }^{51}$ The PARTNER (Placement of Aortic Transcatheter Valve) trial used a valve area of $<0.8 \mathrm{~cm}^{2}$, a peak transvalvular velocity of $\geq 4 \mathrm{~m} / \mathrm{sec}$, or a mean gradient of $\geq 40 \mathrm{mmHg}$ to define "critical aortic stenosis" and select patients appropriate for consideration of transcatheter aortic valve replacement. ${ }^{60}$ Patients with small valve areas but low gradients pose a diagnostic challenge. DSE is very helpful in distinguishing between true severe aortic stenosis and pseudostenosis secondary to reduced left ventricular systolic function. It is particularly helpful in estimating contractile reserve and guiding appropriate therapies. ${ }^{54}$ In addition, for patients with low gradients, normal systolic function, and low flow aortic stenosis, DSE can be helpful in determining the projected valve area under normal flow states and helping guide appropriate therapeutic interventions. ${ }^{61}$

\section{Mitral regurgitation}

Doppler analysis allows the severity of the regurgitant lesion to be quantified, with many echocardiographic parameters contributing to the gradation of severity. The effect of mitral regurgitation on pulmonary pressures and right ventricular function during exercise is a commonly assessed metric. During exercise, an exaggerated rise in pulmonary pressure suggests more severe mitral valve disease than indicated solely by the echocardiographic appearance at rest. ${ }^{62}$ To date, there are limited data describing the utility of DSE in assessing pulmonary pressures and right ventricular function in mitral regurgitation, in part because of the afterload-reducing effect of dobutamine..$^{50}$

\section{Pulmonary hypertension}

Doppler evaluation of the tricuspid valve regurgitant velocity is used to estimate right ventricular systolic pressure with a derivation of the Bernoulli equation (right ventricular systolic pressure and pulmonary artery systolic pressure will be equal except in right ventricular outflow tract obstruction and 
pulmonary stenosis). This Doppler evaluation is feasible both at rest ${ }^{63-65}$ and under stress, and may be helpful in quantifying the severity of pulmonary hypertension as well as detecting occult or exercise-induced pulmonary hypertension. ${ }^{62,65}$ A tricuspid valve regurgitation velocity $\leq 2.5 \mathrm{~m} / \mathrm{sec}$ at rest corresponds to a pulmonary artery systolic pressure of $\leq 35 \mathrm{mmHg}$ (assuming a right atrial pressure of $10 \mathrm{mmHg}$ ) and defines an upper limit of normal at rest. ${ }^{63-65}$ DSE may be utilized for detecting pulmonary hypertension secondary to left-sided valvular disease such as mitral regurgitation and aortic stenosis, although exercise would be preferable to DSE if the patient can exercise, and also preferable for regurgitant lesions. Detection of elevated pulmonary artery pressures during stress predicts poorer outcomes in these patients and should prompt consideration of more aggressive valvular intervention. ${ }^{58,66}$

\section{Pretransplant evaluation}

Patients with end-stage renal disease are at increased risk of CAD, and cardiovascular disease is the most common cause of death after renal transplantation. Therefore, accurate assessment of the extent and severity of CAD prior to renal transplantation is essential. The accuracy of DSE for detecting $\mathrm{CAD}$ in patients with end-stage renal disease has been variable (sensitivities 37\%-95\% and specificities $71 \%-95 \%) .{ }^{67} \mathrm{~A}$ recent large Cochrane analysis of pretransplant cardiac imaging modalities found that DSE is superior to myocardial perfusion scintigraphy for detection of CAD in prerenal transplant patients. ${ }^{68}$ Stress echocardiography is also a pretransplant predictor of mortality. In a recent study of 485 patients with advanced kidney disease (hemodialysisdependent or serum creatinine $>3 \mathrm{mg} / \mathrm{dL}$ ), the number of ischemic segments visualized on DSE independently predicted post-transplant mortality. ${ }^{69}$ Notably, the absence of CAD on preoperative imaging does not necessarily correlate with cardiac event-free survival after transplant. ${ }^{68}$ DSE is also often performed as part of the preoperative evaluation for liver transplantation; its overall sensitivity for CAD is poor, but the test has a reasonable negative predictive value in this population, making it useful to exclude CAD and perioperative events. ${ }^{70-72}$ DSE as an echocardiographic modality also gives the option of estimating right ventricular systolic pressures, which may be important given the possibility of portopulmonary hypertension.

\section{DSE in women}

Women often present with symptoms considered atypical of CAD and are more likely to be underdiagnosed and undertreated. Stress echocardiography provides prognostic information, even after controlling for clinical and laboratory data, in women with known or suspected CAD. ${ }^{73}$ When exercise ECG was directly compared with exercise echocardiography in women, exercise echocardiography had a higher sensitivity (81\% versus $77 \%$ ) and specificity ( $80 \%$ versus $56 \%$ ) for the detection of CAD. Exercise echocardiography also provided the "best balance" between accuracy and cost for the diagnosis of CAD in women. ${ }^{74}$ When echocardiography was compared directly with stress thallium-201 SPECT, there was no difference in diagnostic accuracy. These benefits of exercise echocardiography are believed to be shared by DSE, but exercise would remain the preferred stress modality if the patient is able to exercise. For young and middle-aged women, stress echocardiography avoids the long-term risk of radiation-induced carcinogenesis in other analogous radionuclide-based cardiac imaging modalities. DSE can both accurately restratify women with an intermediate pretest probability of CAD into a low-risk group $^{75}$ and distinguish normal from abnormal to limit unnecessary cardiac catheterization. ${ }^{76}$

\section{Specific testing considerations Poor acoustic windows}

All forms of echocardiography depend on the acquisition of ultrasound images. For patients with a large body habitus, chronic obstructive pulmonary disease, breast implants, or ascites, the quality of the ultrasound images may be compromised and the diagnostic accuracy of the test impaired. Prior to stress testing, the practitioner should consider for each patient which test is most appropriate and will yield the most valuable information for the risks engendered by the procedure. In addition, as discussed above, contrast can be used in some cases to improve the visibility of the endocardium and enhance diagnostic utility. The practitioner may reasonably choose to abort the stress test after inability to obtain diagnostic echocardiographic windows at rest.

\section{Left bundle branch block}

For patients with left bundle branch block, the 2009 American College of Cardiology/American Heart Association guideline updates determined that the sensitivity and specificity of exercise treadmill testing and exercise myocardial perfusion imaging was inadequate, due to the effects of increased chronotropy and increased inotropy on worsening septal paradoxical motion. However, stress echocardiography is still valuable in assessing CAD in patients with left bundle branch block, with higher specificity than myocardial 
perfusion imaging, although somewhat overall reduced sensitivity when there is septal wall motion abnormality on rest echocardiography. ${ }^{77,78}$ The choice of stress modality between exercise and pharmacologic testing in part depends on patient-specific factors and contraindications to a particular stressor modality. Thus, exercise echocardiography is likely overall preferable to DSE, because dobutamine increases chronotropy and inotropy, thereby contributing to paradoxical septal motion. In the case of left bundle branch block in patients unable to exercise, vasodilator myocardial perfusion imaging is recommended for those unable to exercise. ${ }^{79}$ However, there have been preliminary analyses with quantitative metrics such as longitudinal systolic strain and strain rate as assessed by velocity vector imaging during DSE in patients with left bundle branch block. ${ }^{80}$

\section{Hypertensive response}

Patients with a hypertensive response at exercise stress echocardiography (typically systolic blood pressure $>220 \mathrm{mmHg}$ ) have a higher false positive rate of detection of wall motion abnormalities, ie, $22 \%$ compared with $12 \%$ for those without a hypertensive response to stress echocardiography. ${ }^{81}$ In these patients, alternative stress modalities should be considered for subsequent testing (eg, adenosine) or earlier administration of atropine in the protocol may be considered. ${ }^{82}$

\section{Prior myocardial infarction}

The sensitivity of stress echocardiography is higher among patients who have had a prior myocardial infarction compared with those who have not had a prior myocardial infarction (95\% versus $82 \%$ ). However, the specificity of DSE in patients with a prior myocardial infarction is much lower than it is for patients without prior myocardial infarction ( $44 \%$ versus $84 \%$ ), likely due to the difficulty of interpretation of the study when there are baseline wall motion abnormalities. When the infarct size is small or the ischemic event was remote, the specificity of DSE was improved ( $84 \%$ for a small infarct versus $33 \%$ for a large infarct). ${ }^{83}$

\section{Left main and triple vessel CAD}

Left main and/or triple vessel coronary disease are both serious life-threatening phenotypes of CAD. Their detection often alters clinical care by promoting an evaluation for coronary artery bypass grafting surgery. A meta-analysis of 32 studies comparing stress echocardiography and myocardial perfusion imaging in a head-to-head fashion determined that stress echocardiography was the preferred method of testing for detection of proximal left main disease or triple vessel disease. Stress echocardiography had a higher pooled sensitivity (94\% versus 75\%) and a lower negative likelihood ratio (0.21 versus 0.27$)$ when compared with myocardial perfusion imaging. Interestingly, there was no significant difference in the specificities of the two tests $(40 \%$ for stress echocardiography and $48 \%$ for perfusion imaging). ${ }^{84}$

\section{Comparison with other stress modalities}

There are multiple modalities available for the detection and assessment of CAD. Each offers unique advantages and disadvantages. Deciding which modality is optimal depends on the individual patient, their risk profile, and locally available resources and expertise, especially given that the interpretation of stress echocardiography is highly operator-dependent. As with any procedure, centers that perform a high volume of DSE procedures have the highest diagnostic yield and the lowest rate of complications. ${ }^{85}$ All standardized guidelines recommend exercise testing when possible, and both stress echocardiography and SPECT are well established tests. Newer imaging techniques include PET imaging, cardiac computed tomography, and cardiac MRI. PET has high sensitivity and specificity, but its widespread use is limited by cost and the challenges of radionuclide acquisition. Cardiac computed tomography allows for coronary calcium screening but does not offer functional information. It requires a patient to lie flat and cooperate with prolonged breath holds (up to 20 seconds) for the examination. Similarly, cardiac MRI offers the most comprehensive cardiac examination but, like computed tomography, requires the patient to be stable enough to lie flat in an MRI scanner for approximately an hour and cooperate with the more complicated breath holds necessary for optimal image acquisition. Cost and infrastructure requirements limit widespread use of these three newer modalities. ${ }^{86}$

\section{Test characteristics}

Multiple factors affect the accuracy of cardiovascular diagnostic tests (Table 3). Various studies report sensitivities for overall detection of CAD by DSE ranging from 61\%-96\% and specificities ranging from $70 \%-100 \% .{ }^{87}$ In comparison, a large meta-analysis of exercise echocardiography reported sensitivity of $85 \%$ and specificity of $77 \%$ for detection of CAD. ${ }^{30}$ Examination of 62 studies from 1991 to 2006 that included over 6,800 patients found that the sensitivity of DSE was related to inclusion of patients with prior myocardial infarction. Specificity was lower in patients who had pre-existing echocardiographic wall motion abnormalities. In addition, referral bias decreased the specificity of DSE. 
Table 3 Sensitivity and specificity of various ischemic testing modalities

\begin{tabular}{llllll}
\hline & $\begin{array}{l}\text { Exercise } \\
\text { ECG } \\
\mathbf{n}>\mathbf{2 4 , 0 0 0}\end{array}$ & $\begin{array}{l}\text { Thallium } \\
\text { rMPI } \\
\mathbf{n = 5 1 0}\end{array}$ & $\begin{array}{l}\text { SPECT } \\
\mathbf{n = 6 2 8}\end{array}$ & $\begin{array}{l}\text { Stress } \\
\text { echo } \\
\mathbf{n}=\mathbf{1}, \mathbf{1 7 4}\end{array}$ & $\begin{array}{l}\text { PET } \\
\text { scanning }\end{array}$ \\
$\mathbf{n}=\mathbf{2 0 6}$
\end{tabular}

Notes: Adapted from Garber and Solomon. Cost-effectiveness of alternative strategies for the diagnosis of coronary artery disease. Ann Intern Med. 1999: 1 30(90): 719-728. With permission form the American College of Physicians. ${ }^{29}$

Abbreviations: ECG, electrocardiogram; PET, positron emission tomography; rMPI, radionuclide myocardial perfusion imaging; SPECT, single photon emission computed tomography.

Ultimately, the actual specificity of DSE may be lower than expected due to inclusion of patients with prior myocardial infarction (due to the definitions of a positive test) and the negative effects of referral bias. ${ }^{21}$

In addition to patient-specific characteristics, whether or not the maximal age-predicted heart rate is reached has a significant impact on the sensitivity and specificity of DSE. A meta-analysis of over 11,500 patients showed that patients who do not reach their maximal age-predicted heart rate (on both exercise echocardiography and DSE) but have a normal stress echocardiogram have a higher rate of cardiovascular events (nonfatal myocardial infarction and cardiac death) and revascularization than those who achieved their maximal age-predicted heart rate. The risk was nearly three-fold for patients with abnormal stress echocardiography and submaximal heart rate response versus patients with normal stress echocardiography and submaximal heart rate response. ${ }^{88}$

\section{Conclusion}

Since its introduction into clinical practice in 1979, stress echocardiography has played an important role in the evaluation of suspected and known CAD. Dobutamine allows performance of an echocardiographic stress test in patients who would not otherwise be able to exercise. This technique has evolved over the years with technological advancements, including development of contrast echocardiography for endocardial definition. Contrast can also be used for myocardial perfusion analyses..$^{89}$ Contrast enhancement has improved the accuracy of testing and increased the number of eligible patients. ${ }^{90}$ Recent data suggest that stress echocardiography is useful in prognosticating outcomes for patients with various levels of systolic dysfunction, diastolic abnormalities, and valvular heart disease. Furthermore, there is an emerging role for stress echocardiography in evaluation of left ventricular assist devices and in evaluation of potential cardiac transplant donors. ${ }^{91}$ Recent studies have also started to examine myocardial mechanics in the setting of stress echocardiography. ${ }^{92}$ There is still much to be studied, including the added value of assessing ventricular strain, tissue Doppler, and real-time three-dimensional data in DSE, the role and appropriateness of myocardial contrast, application of coronary flow reserve, and the utility of myocardial perfusion techniques. ${ }^{2,85}$ Stress echocardiography is a versatile and well validated tool for cardiovascular diagnostic evaluation and will likely continue to serve as a powerful prognostic tool in years to come.

\section{Disclosure}

The authors report no conflicts of interest in this work.

\section{References}

1. Cheitlin MD. Stress echocardiography in mitral stenosis: When is it useful? J Am Coll Cardiol. 2004;43:402-404.

2. Pellikka PA, Nagueh SF, Elhendy AA, et al. American Society of Echocardiography recommendations for performance, interpretation, and application of stress echocardiography. J Am Soc Echocardiogr. 2007;20:1021-1041.

3. Hays JT, Mahmarian JJ, Cochran AJ, Verani MS. Dobutamine thallium-201 tomography for evaluating patients with suspected coronary artery disease unable to undergo exercise or vasodilator pharmacologic stress testing. J Am Coll Cardiol. 1993;21:1583-1590.

4. Nesto RW, Kowalchuk GJ. The ischemic cascade: temporal sequence of hemodynamic, electrocardiographic and symptomatic expressions of ischemia. Am J Cardiol. 1987;59:23C-30C.

5. Throckmorton DC. Approval package for application number NDA 17-820/S-037. Letter to Eli Lilly and Company, July 23, 2002. Available from: http://www.accessdata.fda.gov/drugsatfda_docs/ nda/2002/17-820_dobutrex_approv.pdf. Accessed October 28, 2013.

6. Picard MH, Adams D, Bierig SM, et al. American Society of Echocardiography recommendations for quality echocardiography laboratory operations. J Am Soc Echocardiogr. 2011;24:1-10.

7. Ling LH, Pellikka PA, Mahoney DW, et al. Atropine augmentation in dobutamine stress echocardiography: role and incremental value in a clinical practice setting. J Am Coll Cardiol. 1996;28:551-557.

8. McNeill AJ, Fioretti PM, el-Said SM, Salustri A, Forster T, Roelandt JR. Enhanced sensitivity for detection of coronary artery disease by addition of atropine to dobutamine stress echocardiography. Am J Cardiol. 1992;70:41-46.

9. Fioretti PM, Poldermans D, Salustri A, et al. Atropine increases the accuracy of dobutamine stress echocardiography in patients taking beta-blockers. Eur Heart J. 1994;15:355-360.

10. Karagiannis SE, Bax JJ, Elhendy A, et al. Enhanced sensitivity of dobutamine stress echocardiography by observing wall motion abnormalities during the recovery phase after acute beta-blocker administration. $\mathrm{Am}$ J Cardiol. 2006;97:462-465.

11. Mathias W, Tsutsui JM, Andrade JL, et al. Value of rapid beta-blocker injection at peak dobutamine-atropine stress echocardiography for detection of coronary artery disease. J Am Coll Cardiol. 2003;41: 1583-1589.

12. Karagiannis SE, Feringa HH, Bax JJ, et al. Myocardial viability estimation during the recovery phase of stress echocardiography after acute beta-blocker administration. Eur J Heart Fail. 2007;9:403-408.

13. Shehata AR, Gillam LD, Mascitelli VA, et al. Impact of acute propranolol administration on dobutamine-induced myocardial ischemia as evaluated by myocardial perfusion imaging and echocardiography. Am J Cardiol. 1997;80:268-272. 
14. Sicari R, Cortigiani L, Bigi R, et al; Echo-Dobutamine International Cooperative Study Group. Prognostic value of pharmacological stress echocardiography is affected by concomitant antiischemic therapy at the time of testing. Circulation. 2004;109:2428-2431.

15. Kane GC, Hepinstall MJ, Kidd GM, et al. Safety of stress echocardiography supervised by registered nurses: results of a 2-year audit of 15,404 patients. J Am Soc Echocardiogr. 2008;21:337-341.

16. Douglas PS, Garcia MJ, Haines DE, et al. 2011 appropriate use criteria for echocardiography. J Am Coll Cardiol. 2011;57:1126-1166.

17. Nakajima Y, Kane GC, McCully RB, Ommen SR, Pellikka PA. Left ventricular diastolic filling pressures during dobutamine stress echocardiography: relationship to symptoms and ischemia. J Am Soc Echocardiogr. 2009;22:947-953.

18. Ha JW, Oh JK, Pellikka PA, et al. Diastolic stress echocardiography: a novel noninvasive diagnostic test for diastolic dysfunction using supine bicycle exercise doppler echocardiography. J Am Soc Echocardiogr. 2005;18:63-68.

19. Pellikka PA, Roger VL, Oh JK, Seward JB, Tajik AJ. Safety of performing dobutamine stress echocardiography in patients with abdomina aortic aneurysm $>$ or $=4 \mathrm{~cm}$ in diameter. Am J Cardiol. 1996;77: 413-416.

20. Takhtehchian DS, Novaro GM, Barnett G, Griffin BP, Pellikka PA. Safety of dobutamine stress echocardiography in patients with unruptured intracranial aneurysms. J Am Soc Echocardiogr. 2002;15: 1401-1404.

21. Geleijnse ML, Krenning BJ, van Dalen BM, et al. Factors affecting sensitivity and specificity of diagnostic testing: dobutamine stress echocardiography. J Am Soc Echocardiogr. 2009;22:1199-1208.

22. Wuthiwaropas P, Wiste JA, McCully RB, Kane GC, Scott CG, Pellikka PA. Neuropsychiatric symptoms during 24 hours after dobutamine-atropine stress testing: a prospective study in 1,006 patients. J Am Soc Echocardiogr. 2011;24:367-373.

23. Verani MS. Pharmacologic stress myocardial perfusion imaging. Curr Probl Cardiol. 1993;18:481-525.

24. Iskandrian AS, Verani MS, Heo J. Pharmacologic stress testing: mechanism of action, hemodynamic responses, and results in detection of coronary artery disease. J Nucl Cardiol. 1994;1:94-111.

25. Ryan T, Feigenbaum H. Exercise echocardiography. Am J Cardiol. 1992;69:82H-89H.

26. Kamaran M, Teague SM, Finkelhor RS, Dawson N, Bahler RC. Prognostic value of dobutamine stress echocardiography in patients referred because of suspected coronary artery disease. Am J Cardiol. 1995;76:887-891.

27. Ryan T, Segar DS, Sawada SG, et al. Detection of coronary artery disease with upright bicycle exercise echocardiography. J Am Soc Echocardiogr. 1993;6:186-197.

28. Hecht HS, DeBord L, Shaw R, et al. Digital supine bicycle stress echocardiography: A new technique for evaluating coronary artery disease. J Am Coll Cardiol. 1993;21:950-956.

29. Garber AM, Solomon NA. Cost-effectiveness of alternative test strategies for the diagnosis of coronary artery disease. Ann Intern Med. 1999;130:719-728.

30. Fleischmann KE, Hunink MG, Kuntz KM, Douglas PS. Exercise echocardiography or exercise SPECT imaging? A meta-analysis of diagnostic test performance. J Am Med Assoc. 1998;280:913-920.

31. Metz LD, Beattie M, Hom R, Redberg RF, Grady D, Fleischmann KE. The prognostic value of normal exercise myocardial perfusion imaging and exercise echocardiography: a meta-analysis. J Am Coll Cardiol. 2007;49:227-237.

32. Shaw LJ, Vasey C, Sawada S, Rimmerman C, Marwick TH. Impact of gender on risk stratification by exercise and dobutamine stress echocardiography: long-term mortality in 4234 women and 6898 men. Eur Heart J. 2005;26:447-456.

33. Marwick T, D'Hondt AM, Baudhuin T, et al. Optimal use of dobutamine stress for the detection and evaluation of coronary artery disease: Combination with echocardiography or scintigraphy, or both? $\mathrm{J} \mathrm{Am}$ Coll Cardiol. 1993;22:159-167.
34. Alderman EL, Fisher LD, Litwin P, et al. Results of coronary artery surgery in patients with poor left ventricular function (CASS). Circulation. 1983;68:785-795.

35. Pigott JD, Kouchoukos NT, Oberman A, Cutter GR. Late results of surgical and medical therapy for patients with coronary artery disease and depressed left ventricular function. J Am Coll Cardiol. 1985;5:1036-1045.

36. Rees G, Bristow JD, Kremkau EL, et al. Influence of aortocoronary bypass surgery on left ventricular performance. New Engl J Med. 1971;284:1116-1120.

37. Chatterjee K, Swan HJ, Parmley WW, Sustaita H, Marcus HS, Matloff J. Influence of direct myocardial revascularization on left ventricular asynergy and function in patients with coronary heart disease. With and without previous myocardial infarction. Circulation. 1973;47:276-286.

38. Brundage BH, Massie BM, Botvinick EH. Improved regional ventricular function after successful surgical revascularization. J Am Coll Cardiol. 1984;3:902-908.

39. Cheirif J, Murgo JP. Assessment of myocardial viability by dobutamine echocardiography. Coron Artery Dis. 1995;6:600-605.

40. Cornel JH, Bax JJ, Elhendy A, et al. Biphasic response to dobutamine predicts improvement of global left ventricular function after surgical revascularization in patients with stable coronary artery disease: Implications of time course of recovery on diagnostic accuracy. J Am Coll Cardiol. 1998;31:1002-1010.

41. Gamici PG, Prasad SK, Rimoldi OE. Stunning, hibernation, and assessment of myocardial viability. Circulation. 2008;117:103-114.

42. Meluzín J, Cerný J, Frélich M, et al. Prognostic value of the amount of dysfunctional but viable myocardium in revascularized patients with coronary artery disease and left ventricular dysfunction. J Am Coll Cardiol. 1998;32:912-920.

43. Smart SC, Knickelbine T, Stoiber TR, Carlos M, Wynsen JC, Sagar KB. Safety and accuracy of dobutamine-atropine stress echocardiography for the detection of residual stenosis of the infarct-related artery and multivessel disease during the first week after acute myocardial infarction. Circulation. 1997;95:1394-1401.

44. Nijland F, Kamp O, Verhorst PM, de Voogt WG, Visser CA. In-hospital and long-term prognostic value of viable myocardium detected by dobutamine echocardiography early after acute myocardial infarction and its relation to indicators of left ventricular systolic dysfunction. Am J Cardiol. 2001;88:949-955.

45. Picano E, Sicari R, Landi P, et al. Prognostic value of myocardial viability in medically treated patients with global left ventricular dysfunction early after an acute uncomplicated myocardial infarction: a dobutamine stress echocardiographic study. Circulation. 1998;98:1078-1084.

46. Afridi I, Grayburn PA, Panza JA, Oh JK, Zoghbi WA, Marwick TH. Myocardial viability during dobutamine echocardiography predicts survival in patients with coronary artery disease and severe left ventricular systolic dysfunction. J Am Coll Cardiol. 1998;32:921-926.

47. Sawada SG, Lewis SJ, Foltz J, et al. Usefulness of rest and low-dose dobutamine wall motion scores in predicting survival and benefit from revascularization in patients with ischemic cardiomyopathy. Am J Cardiol. 2002;89:811-816.

48. Afridi I, Kleiman NS, Raizner AE, Zoghbi WA. Dobutamine echocardiography in myocardial hibernation. Optimal dose and accuracy in predicting recovery of ventricular function after coronary angioplasty. Circulation. 1995;91:663-670.

49. Ma L, Chen L, Gillam L, Waters DD, Chen C. Nitroglycerin enhances the ability of dobutamine stress echocardiography to detect hibernating myocardium. Circulation. 1997;96:3992-4001.

50. Pierard LA, Lancellotti P. Stress testing in valve disease. Heart. 2007;93:766-772.

51. Bonow RO, Carabello BA, Chatterjee K, et al. 2008 Focused Update Incorporated into the ACC/AHA 2006 Guidelines for the Management of Patients with Valvular Heart Disease. Circulation. 2008;118:e523-e661.

52. Reis G, Motta MS, Barbosa MM, Esteves WA, Souza SF, Bocchi EA. Dobutamine stress echocardiography for noninvasive assessment and risk stratification of patients with rheumatic mitral stenosis. J Am Coll Cardiol. 2004;43:393-401. 
53. deFilippi CR, Willett DL, Brickner ME, et al. Usefulness of dobutamine echocardiography in distinguishing severe from nonsevere valvular aortic stenosis in patients with depressed left ventricular function and low transvalvular gradients. Am J Cardiol. 1995;75:191-194.

54. Grayburn PA. Assessment of low-gradient aortic stenosis with dobutamine. Circulation. 2006;113:604-606

55. Lin SS, Roger VL, Pascoe R, Seward JB, Pellikka PA. Dobutamine stress doppler hemodynamics in patients with aortic stenosis: feasibility, safety, and surgical correlations. Am Heart J. 1998;136:1010-1016.

56. Baumgartner $\mathrm{H}$, Hung J, Bermejo J, et al. Echocardiographic assessment of valve stenosis: EAE/ASE recommendations for clinical practice. $J$ Am Soc Echocardiogr. 2009;22:1-23.

57. Monin JL, Quere JP, Monchi M, et al. Low-gradient aortic stenosis: operative risk stratification and predictors for long-term outcome: a multicenter study using dobutamine stress hemodynamics. Circulation. 2003;108:319-324.

58. O'Connor K, Lancellotti P, Donal E, Pierard LA. Exercise echocardiography in severe asymptomatic aortic stenosis. Arch Cardiovasc Dis. 2010;103:262-269.

59. Zamorano JL, Badano LP, Bruce C, et al. EAE/ASE recommendations for the use of echocardiography in new transcatheter interventions for valvular heart disease. Eur J Echocardiogr. 2011;12:557-584.

60. Leon MB, Smith CR, Mack M, et al. Transcatheter aortic-valve implantation for aortic stenosis in patients who cannot undergo surgery. $N E n g l$ J Med. 2010;363:1597-1607.

61. Blais C, Burwash IG, Mundigler G, et al. Projected valve area at normal flow rate improves the assessment of stenosis severity in patients with low-flow, low-gradient aortic stenosis: the multicenter TOPAS (truly or pseudo-severe aortic stenosis) study. Circulation. 2006;113:711-721.

62. Himelman RB, Stulbarg MS, Lee E, Kuecherer HF, Schiller NB. Noninvasive evaluation of pulmonary artery systolic pressures during dynamic exercise by saline-enhanced doppler echocardiography. Am Heart J. 1990;119:685-688.

63. Hatle L, Angelsen BA, Tromsdal A. Non-invasive estimation of pulmonary artery systolic pressure with doppler ultrasound. Br Heart J. 1981;45:157-165.

64. Yock PG, Popp RL. Noninvasive estimation of right ventricular systolic pressure by Doppler ultrasound in patients with tricuspid regurgitation. Circulation. 1984;70:657-662.

65. Himelman RB, Schiller NB. Exercise Doppler: functional evaluation of right heart dynamics. Echocardiography. 1992;9:225-233.

66. Kusunose K, Popovic ZB, Motoki H, Marwick TH. Prognostic significance of exercise-induced right ventricular dysfunction in asymptomatic degenerative mitral regurgitation. Circ Cardiovasc Imaging. 2013;6:167-176.

67. Lentine KL, Hurst FP, Jindal RM, et al. Cardiovascular risk assessment among potential kidney transplant candidates: approaches and controversies. Am J Kidney Dis. 2010;55:152-167.

68. Wang LW, Fahim MA, Hayen A, et al. Cardiac testing for coronary artery disease in potential kidney transplant recipients. Cochrane Database Syst Rev. 2011;12:CD008691.

69. Bergeron S, Hillis GS, Haugen EN, Oh JK, Bailey KR, Pellikka PA. Prognostic value of dobutamine stress echocardiography in patients with chronic kidney disease. Am Heart J. 2007;153:385-391.

70. Nguyen P, Plotkin J, Fishbein TM, et al. Dobutamine stress echocardiography in patients undergoing orthotopic liver transplantation: a pooled analysis of accuracy, perioperative and long term cardiovascular prognosis. Int J Cardiovasc Imaging. 2013;29:1741-1748.

71. Findlay JY, Keegan MT, Pellikka PP, Rosen CB, Plevak DJ. Preoperative dobutamine stress echocardiography, intraoperative events, and intraoperative myocardial injury in liver transplantation. Transplant Proc. 2005;37:2209-2213.

72. Harinstein ME, Flaherty JD, Ansari AH, et al. Predictive value of dobutamine stress echocardiography for coronary artery disease detection in liver transplant candidates. Am J Transplant. 2008;8:1523-1528.

73. Heupler S, Mehta R, Lobo A, Leung D, Marwick TH. Prognostic implications of exercise echocardiography in women with known or suspected coronary artery disease. J Am Coll Cardiol. 1997;30:414-420.
74. Marwick TH, Anderson T, Williams MJ, et al. Exercise echocardiography is an accurate and cost-efficient technique for detection of coronary artery disease in women. J Am Coll Cardiol. 1995;26:335-341.

75. Davar JI, Brull DJ, Bulugahipitiya S, Coghlan JG, Lipkin DP, Evans TR. Prognostic value of negative dobutamine stress echo in women with intermediate probability of coronary artery disease [Abstract]. $\mathrm{Am} J$ Cardiol. 1999;83(1):100-102, A8.

76. Ho YL, Wu CC, Huang PJ, et al. Assessment of coronary artery disease in women by dobutamine stress echocardiography: comparison with stress thallium-201 single-photon emission computed tomography and exercise electrocardiography. Am Heart J. 1998;135:655-662.

77. Cortigiani L, Picano E, Vigna C, et al. Prognostic value of pharmacologic stress echocardiography in patients with left bundle branch block. Am J Med. 2001;110:361-369.

78. Sicari R. Risk stratification by stress echocardiography beyond wall motion analysis. JACC Cardiovasc Imaging. 2009;2:260-262.

79. Fleisher LA, Beckman JA, Brown KA, et al. 2009 ACCF/AHA Focused update on perioperative beta blockade incorporated into the ACC/AHA 2007 guidelines on perioperative cardiovascular evaluation and care for noncardiac surgery. Circulation. 2009;120:e169-e276.

80. Shan Y, Villarraga HR, Pislaru C, Shah AA, Cha SS, Pellikka PA. Quantitative assessment of strain and strain rate by velocity vector imaging during dobutamine stress echocardiography to predict outcome in patients with left bundle branch block. J Am Soc Echocardiogr. 2009;22:1212-1219.

81. Ha JW, Juracan EM, Mahoney DW, et al. Hypertensive response to exercise: a potential cause for new wall motion abnormality in the absence of coronary artery disease. J Am Coll Cardiol. 2002;39:323-327.

82. Lee CY, Pellikka PA, Shub C, Sinak LJ, Seward JB. Hypertensive response during dobutamine stress echocardiography. Am J Cardiol. 1997;80:970-971.

83. Nishioka T, Mitani H, Uehata A, et al. Utility and limitation of treadmill exercise echocardiography for detecting significant coronary stenosis in infarct-related arteries in patients with healed myocardial infarction. Am J Cardiol. 2002;89:159-163.

84. Mahajan N, Polavaram L, Vankayala H, et al. Diagnostic accuracy of myocardial perfusion imaging and stress echocardiography for the diagnosis of left main and triple vessel coronary artery disease: a comparative meta-analysis. Heart. 2010;96:956-966.

85. Sicari R, Nihoyannopoulos P, Evangelista A, et al. Stress echocardiography expert consensus statement: European Association of Echocardiography. Eur J Echocardiogr. 2008;9:415-437.

86. Mastouri R, Sawada SG, Mahenthiran J. Current noninvasive imaging techniques for detection of coronary artery disease. Exp Rev Cardiovasc Ther. 2010;8:77-91.

87. Marwick TH. Stress echocardiography with nonexercise techniques: principles, protocols, interpretation, and clinical applications. In: Otto C, editor. The Clinical Practice of Clinical Echocardiography. Philadelphia, PA, USA: Saunders Elsevier; 2007.

88. Makani H, Bangalore S, Halpern D, Makwana HG, Chaudhry FA. Cardiac outcomes with submaximal normal stress echocardiography: a meta-analysis. J Am Coll Cardiol. 2012;60:1393-1401.

89. Armstrong WF, Ryan T. Stress echocardiography from 1979 to present. J Am Soc Echocardiogr. 2008;21:22-28.

90. Steeds RP. Echocardiography: frontier imaging in cardiology. $\mathrm{Br} J$ Radiol. 2011;84 Spec No 3:S237-S245.

91. Cullen MW, Pellikka PA. Recent advances in stress echocardiography. Curr Opin Cardiol. 2011;26:379-384.

92. Ng AC, Sitges M, Pham PN, et al. Incremental value of 2-dimensional speckle tracking strain imaging to wall motion analysis for detection of coronary artery disease in patients undergoing dobutamine stress echocardiography. Am Heart J. 2009;158:836-844.

93. Geleijnse ML, Krenning BJ, Nemes A, et al. Incidence, pathophysiology, and treatment of complications during dobutamine-atropine stress echocardiography. Circulation. 2010;121:1756-1767. 
Research Reports in Clinical Cardiology

Dovepress

\section{Publish your work in this journal}

Research Reports in Clinical Cardiology is an international, peerreviewed, open access journal publishing original research, reports, editorials, reviews and commentaries on all areas of cardiology in the clinic and laboratory. The manuscript management system is completely online and includes a very quick and fair peer-review system.

Visit http://www.dovepress.com/testimonials.php to read real quotes from published authors.

Submit your manuscript here: http://www.dovepress.com/research-reports-in-clinical-cardiology-journal 